Gut and Liver, Vol. 9, No. 4, July 2015, pp. 437-448

\title{
Management of Hepatocellular Carcinoma: Current Status and Future Directions
}

\author{
Jennifer S. Au* and Catherine T. Frenette ${ }^{\dagger}$ \\ ${ }^{*}$ Division of Gastroenterology and Hepatology, Scripps Clinic, and ${ }^{\dagger}$ Liver Transplantation, Center for Organ and Cell Transplantation, Scripps \\ Clinic, La Jolla, CA, USA
}

Hepatocellular carcinoma (HCC) is the second most common cause of cancer death worldwide. This cancer commonly arises against a background of chronic liver disease. As a result, a patient with HCC requires multidisciplinary care. Treatment options vary widely based on tumor burden and metastases. The most widely utilized staging system is the Barcelona Clinic Liver Cancer staging system, which recommends treatments based on tumor size and the underlying liver disease and functional status of the patient. Treatment options range from surgical resection or transplantation to locoregional therapies with modalities such as radiofrequency ablation and transarterial chemoembolization to systemic chemotherapies. Future care involves the development of combination therapies that afford the best tumor response, further clarification of the patients best suited for therapies and the development of new oral chemotherapeutic agents.

(Gut Liver 2015;9:437-448)

Key Words: Carcinoma, hepatocellular; Transarterial chemoembolization; Radiofrequency ablation; Staging systems; Sorafenib

\section{INTRODUCTION}

Hepatocellular carcinoma (HCC) is the fifth most common cancer in men and ninth most common in women, however the second most common cause of death from cancer worldwide. ${ }^{1}$ In the United States, it is estimated that there will be 26,500 new cases of HCC in 2014. Death rates from HCC have increased by $2.3 \%$ in men and $1.4 \%$ in women in the United States from 2006 to $2010 .^{2}$ The incidence of HCC is highest in those with hepatitis B and hepatitis $C$ related cirrhosis, however even those with noncirrhotic hepatitis C virus (HCV) or hepatitis B virus
(HBV) are at increased risk for HCC. Patients with cirrhosis, no matter the etiology, are at increased risk for the development of HCC. American Association for the Study of Liver Diseases (AASLD) guidelines recommend screening at risk populations for HCC every 6 months with an ultrasound, ${ }^{3}$ although other societies recommend $\alpha$-fetoprotein in addition to ultrasound for improved sensitivity of screening. ${ }^{4}$ Those who are not found to have HCC until symptoms arise have a $0 \%$ to $10 \%$ 5-year survival, whereas those whose HCCs are detected at an early stage have a 5 -year survival that exceeds 50\% with appropriate treatment. $^{5}$

\section{STAGING SYSTEMS}

The prognosis of HCC is related to the tumor stage at presentation. The majority of solid tumor malignancies are staged by the tumor-lymph node-metastasis (TNM) system. ${ }^{6}$ However, as the majority of HCCs arise with a background of chronic liver disease which also greatly influences survival, the TNM system has been found a poor prognostic tool. ${ }^{7}$ In 1971 the International Symposium of Liver Cancer, who convened in Kampala, Uganda, noted that ascites, weight loss, portal hypertension and bilirubin, surrogate markers for hepatic function, were poor prognostic indicators in 72 patients with HCC. ${ }^{7}$ The Kampala system did not gain widespread use as it was noted that a large proportion of the African patients studied had aggressive HCC without underlying cirrhosis. In other countries, HCC more commonly arose in a background of cirrhosis and a higher mortality could be attributed to cirrhosis alone rather than HCC. ${ }^{8}$

In 1985 the Okuda staging system was introduced. The Okuda staging was developed by studying 850 HCC patients. It incorporates an estimate of the percentage of tumor involvement in the liver as well as three markers of liver function; ascites,

Correspondence to: Catherine T. Frenette

Liver Transplantation, Center for Organ and Cell transplantation, Scripps Clinic, 10666 North Torrey Pines Road, N203, La Jolla, CA 92037, USA

Tel: +1-858-554-4310, Fax: +1-858-554-3009, E-mail: Frenette.catherine@scrippshealth.org

Received on January 14, 2015. Accepted on March 30, 2015.

pISSN 1976-2283 eISSN 2005-1212 http://dx.doi.org/10.5009/gnl15022

@) This is an Open Access article distributed under the terms of the Creative Commons Attribution Non-Commercial License (http://creativecommons.org/licenses/by-nc/4.0) which permits unrestricted non-commercial use, distribution, and reproduction in any medium, provided the original work is properly cited. 
albumin, and bilirubin. ${ }^{8}$ It does not take into account number of HCC lesions, size of the lesions, lymph node or vascular metastasis. ${ }^{9}$ As screening started diagnosing HCC at an earlier stage and more treatment options were developed, the Okuda system was felt to be inadequate in stratifying patients with mild disease. Since that time, many other staging systems have been developed, but did not gain widespread use. ,10,11 $^{7}$

The most popular staging system utilized today is the Barcelona Clinic Liver Cancer (BCLC) staging system. The BCLC algorithm was developed by a panel of HCC experts during a meeting in 1999. The system, derived from data obtained in several cohort studies and randomized control trials, stages patients based on extent of HCC, severity of underlying liver disease, as well as performance status. The stages not only estimate life expectancy, but are also linked to recommended treatment strategies. ${ }^{12}$ Those recommendations have also been updated with new developments in the treatment of HCC, such as sorafenib in the treatment of advanced HCC. ${ }^{13,14}$ The BCLC algorithm identified five different stages. In stage 0, patients have Child-Pugh A cirrhosis with a tumor $<2 \mathrm{~cm}$, lack of vascular invasion and are recommended to undergo resection with a 5-year survival of $87 \%$ to $93 \%$. Stages A-C, the intermediate stages, differentiate those who can undergo curative treatments from those more suitable for palliative therapies. Stage A patients with a performance status of 0, Child-Pugh A cirrhosis and one HCC or four nodules all $<3 \mathrm{~cm}$ are treated with the goal of cure and a 5-year survival of $50 \%$ to $75 \%$. Stage D patients are end stage with poor performance status, Child-Pugh C cirrhosis and/or disseminated disease in which case symptomatic treatment is the sole recommendation. The BCLC has been externally validated and is currently the most widely utilized staging system (Fig. 1).,15

One place where the BCLC staging has not been widely accepted is Asia. This is due to the fact that most patients involved in the studies to develop the BCLC algorithm were patients

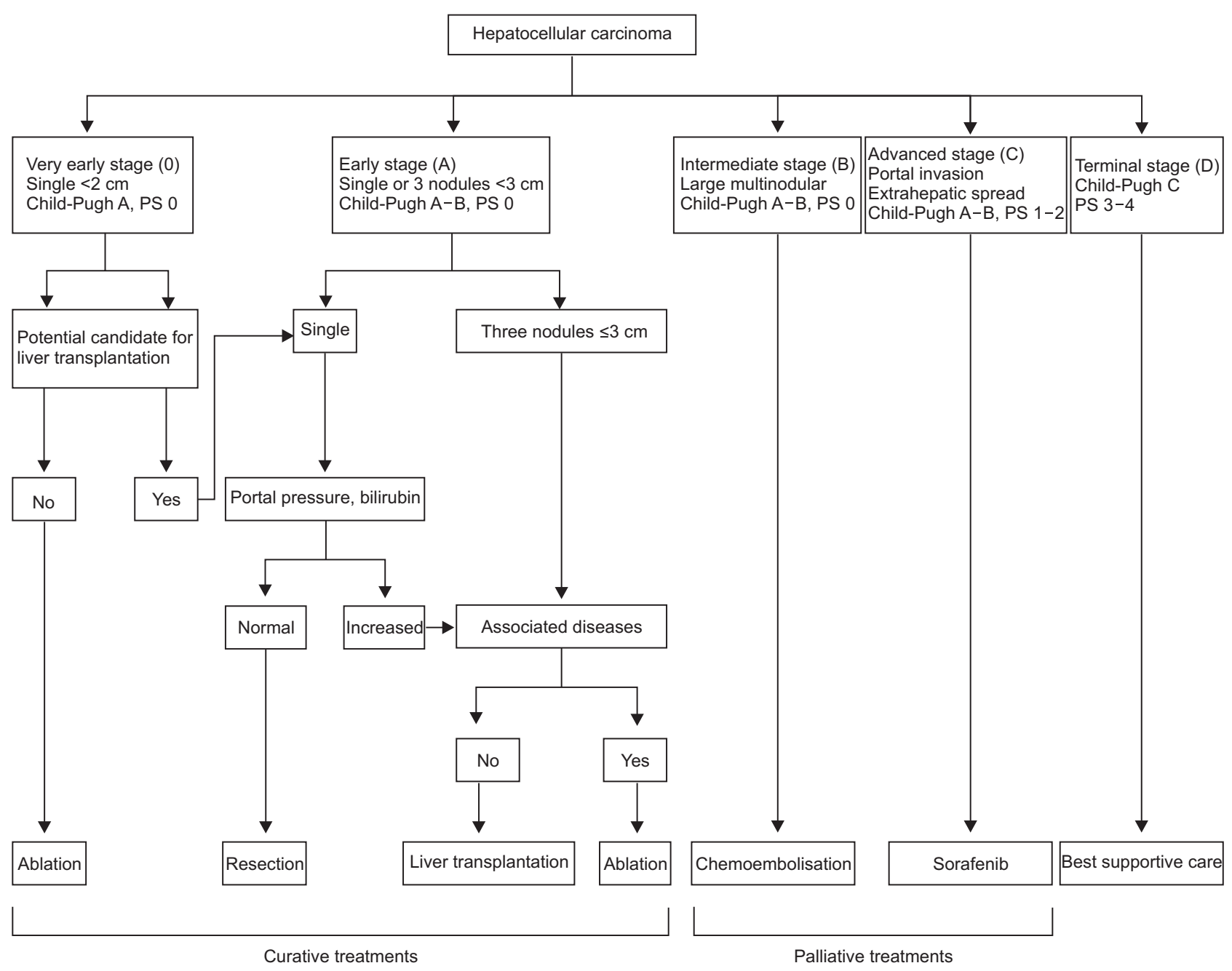

Fig. 1. Barcelona Clinic Liver Cancer staging system. This staging system categorizes patients into one of five stages based on the number and size of tumors, vascular invasion, Child-Pugh score, and Eastern Cooperative Oncology Group status. Each stage correlates with a recommended treatment modality (Adapted from Llovet JM, et al. Liver Transpl 2004;10(2 Suppl 1):S115-S120, with permission from John Wiley and Sons). ${ }^{12}$ PS, performance status. 
with underlying HCV and commonly cirrhosis who developed HCC. In Asia, the majority of patients who develop HCC have underlying HBV who will often have preserved hepatic function and no cirrhosis. Retained hepatic function in addition to a higher surgical expertise has led to a more aggressive approach to treatment in Asian patients. Reflective of this, Yau et al. ${ }^{16}$ recently described the Hong Kong Liver Cancer (HKLC) staging system aimed at guiding the treatment of HCC in Asian patients. The HKLC classification uses four prognostic markers: Eastern Cooperative Oncology Group (ECOG) performance status, ChildPugh class, liver tumor status, and the presence of extrahepatic vascular invasion or metastasis. Similarly to the BCLC scheme, the HKLC stages correlate with a prognosis as well as a recommended treatment strategy. The HKLC classification subgroups those with intermediate and late stage disease to risk stratify patients further than the BCLC and recommends more aggressive treatment which resulted in better survival outcomes with the HKLC in the retrospective cohort. Due to its recent development and evaluation in a retrospective study, prospective, randomized studies are needed before the efficacy of the HKLC algorithm can be determined (Fig. 2).

\section{TREATMENT}

Even with the guidance of a treatment algorithm, the treatment of a patient with HCC can be complex. Typically, multiple treatment modalities are utilized and not only does the HCC need to be treated, but the underlying liver disease will often require medical attention in addition. As a result, HCC patients are best cared for by multidisciplinary teams (MDT). These teams are typically comprised of hepatologists, oncologists, hepatobiliary and transplant surgeons, interventional radiologists, radiation oncologists, and radiologists. The use of an MDT has been recommended by the AASLD; however, studies have shown that only $44 \%$ of patients routinely utilized the MDT approach to the treatment of HCC. ${ }^{3,17}$ Chang et al. ${ }^{18}$ formed an MDT at the San Francisco Veteran's Affair Hospital to care for patients with HCC and created a prospective database. A comparison of patients cared for by the MDT versus those cared for prior to the implementation of the MDT noted that the MDT doubled the number of patients referred for treatment. In addition, more patients were evaluated at an earlier stage and received therapy which increased overall survival and length of follow-up in patients with HCC.

The recommendation to routinely screen for HCC in high risk

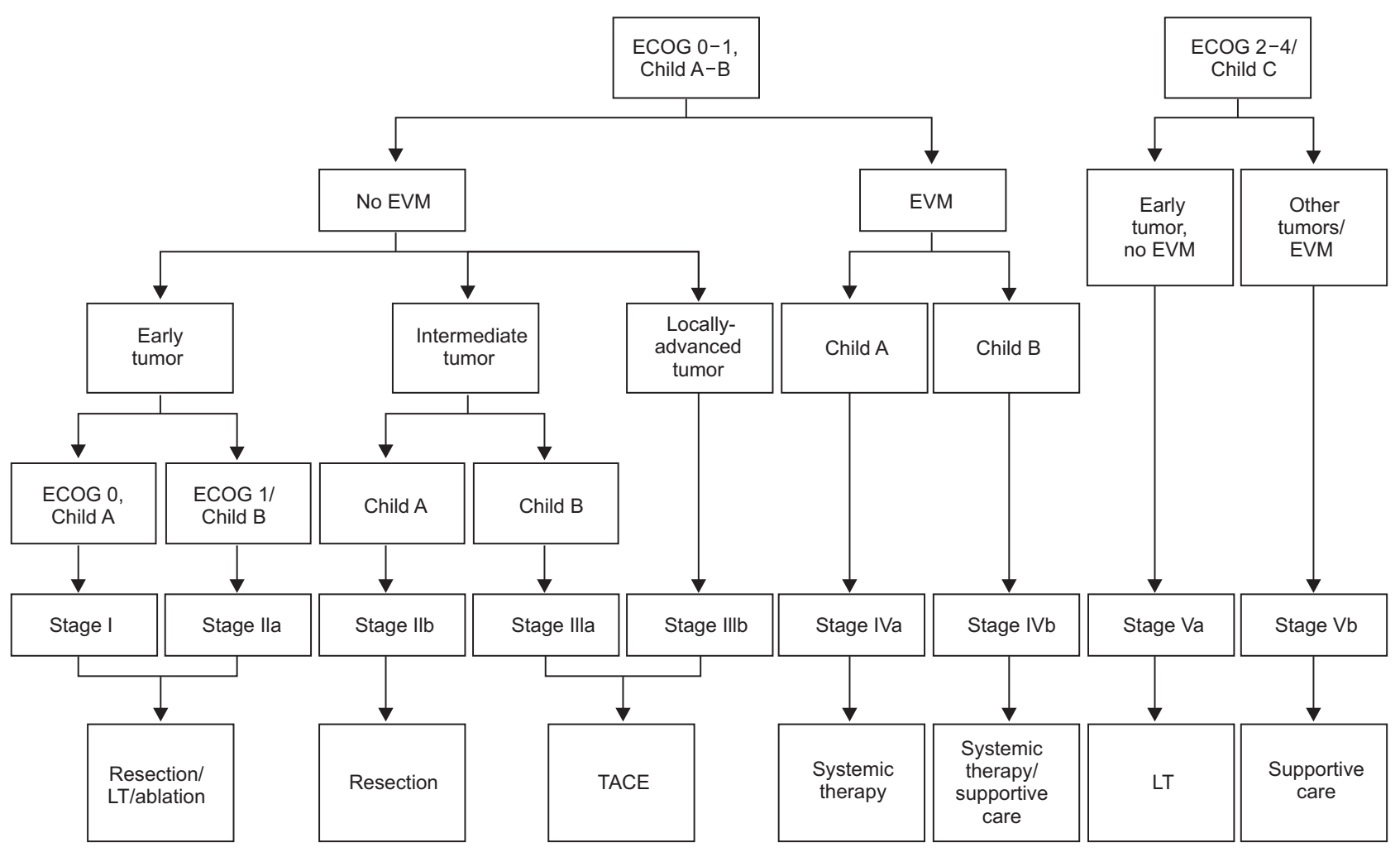

Fig. 2. Hong Kong Liver Clinic staging system. Early tumor: $<5 \mathrm{~cm},<3$ tumor nodules and no intrahepatic venous invasion. Intermediate tumor: (1) $<5 \mathrm{~cm}$, either $>3$ tumor nodules or with intrahepatic venous invasion, or (2) $>5 \mathrm{~cm},<3$ tumor nodules and no intrahepatic venous invasion; and locally advanced tumor: (1) $<5 \mathrm{~cm},>3$ tumor nodules and with intrahepatic venous invasion, or (2) $>5 \mathrm{~cm},>3$ tumor nodules and/or intrahepatic venous invasion, or (3) diffuse tumor (From Yau T, et al. Gastroenterology 2014;146:1691-1700.e3, with permission from Elsevier). ${ }^{16}$

ECOG, Eastern Cooperative Oncology Group; EVM, extrahepatic vascular invasion; LT, liver transplantation; TACE, transarterial chemoembolization. 
populations has increased the diagnosis of early stage disease. ${ }^{3}$ At earlier stages of disease, liver function is typically preserved and there are no symptoms related to the malignancy which affords more treatment options and increases the change of longterm cure. In early stage disease, there is a dearth of knowledge as to which treatment modalities afford the best outcomes. ${ }^{3}$

\section{Surgical resection}

One of the most common treatment options in the noncirrhotic patient with HCC is surgical resection. In Western countries this accounts for 5\% of patients. In Asia, approximately $40 \%$ of patients are candidates for resection due to the severity of the underlying liver disease and surgical experience and expertise. ${ }^{16,19}$ Over time, outcomes for liver resection have improved. This is due in part to identification of HCC at earlier stages when tumors are smaller and without metastases in addition to improved patient selection and surgical techniques. Predictor of decreased survival after resection include larger tumors, poorly differentiated tumors, and more importantly lymph node or vascular metastases. ${ }^{20}$ Historically, Child-Pugh classification was utilized to identify patients best suited for hepatectomy. This was later shown to be an inadequate measure for hepatic function and in fact, bilirubin and portal hypertension, as measured by a hepatic vein pressure gradient $>10 \mathrm{~mm}$ $\mathrm{Hg}$, are better predictors. Those with a normal bilirubin and portal venous pressure had 5-year survival of more than 70\%. ${ }^{21}$ The extent of the hepatectomy performed to HCC removal is now less than it was historically due in part to the use of intraoperative ultrasound. Decreased hepatic resection reduced the amount of postoperative liver failure and morbidity. ${ }^{22}$

Despite increasing overall survival in patient undergoing hepatic resection to treat HCC, the disease-free survival has not changed. Most patients have recurrence of HCC within the first 2 years after resection. Those who recur later often represent a de novo HCC. The factors most predictive of HCC recurrence are tumor differentiation on pathology, vascular invasion and metastasis prior to resection. ${ }^{18,22}$ Use of transarterial chemoembolization (TACE) prior to resection has not shown to improve the rate of local or metastatic recurrence, disease-free or overall survival. $^{23-25}$ The use of adjuvant chemotherapy, adoptive immunotherapy, and retinoids to prevent HCC recurrence have also been utilized with varying results, although none have strong studies behind them to support their use. ${ }^{26-31}$ Interferon therapy after resection has shown benefit in reducing rates of HCC recurrence in patients with underlying viral hepatitis. However, due to the morbidity associated with interferon therapy and discussion as to whether the effect of decreased recurrence is due to treatment of the underlying liver disease or an effect on the neoplasm itself, the use of interferon postresection has not become widespread. $^{32,33}$ It is unclear whether treating underlying hepatitis C with noninterferon based therapies will offer the same benefits to patients after HCC resection.
Those patients who have early recurrence which is unifocal, small with a background of preserved liver function can often benefit from salvage transplantation. ${ }^{34}$ Most patients who recur do so within 2 years and often with disseminated HCC owing to a more aggressive tumor biology, therefore are often not ideal candidates for transplantation. ${ }^{3}$

\section{Liver transplantation}

One of the first indications for liver transplantation was HCC which could not be removed by a hepatic resection. Those first patients who had liver transplantations for HCC were noted to have high rates of HCC recurrence. ${ }^{35,36}$ When further evaluating which patients recurred, it was noted that those who underwent transplantations for underlying cirrhosis and were incidentally found to have an HCC had a much lower rate of recurrence after transplant than those who underwent transplant due to unresectable HCC. ${ }^{37}$ Continued experience showed that patients could be successfully treated with liver transplantation and in 1996, Mazzaferro et al. ${ }^{38}$ set forth the Milan criteria. The Milan criteria states that for patients with HCC who have a single lesion $<5 \mathrm{~cm}$ or no more than three lesions with no lesion being $>3 \mathrm{~cm}$ in diameter had a 67\% to 75\% 5-year survival after transplant, equivalent to those patients transplanted without HCC. The Milan criteria were adopted by United Network for Organ Sharing in 2002. In order to prioritize those with the highest risk of early mortality, patients with HCC are awarded exception points to reflect wait list 90-day mortality or waitlist dropout rate of $15 \%{ }^{3}$ The adoption of the Milan criteria led to an increase of patients transplanted for HCC from 4.6\% prior and 26\% after institution of the Milan criteria with exception points. $^{39}$ Subsequent analyses of the changes to organ allocation for HCC have shown that the exception points place HCC patients at an advantage in terms of transplant and that those listed without HCC are at a disadvantage. ${ }^{39-41}$ HCC patients have lower rates of drop off from the list due to disease progression and death and are less adversely affected by increased wait times on the transplant list. ${ }^{42,43}$ There is much discussion currently regarding the appropriate amount of exception points to award patients with HCC, to be fair to those patients without HCC. The exception system will likely be revised in the next several years.

There is also a large number of HCC patients do not meet the strict Milan criteria and some patients who have tumor burden outside Milan criteria may also benefit from transplant. Yao et al., ${ }^{44}$ in a study of 70 HCC patients, noted that those with one tumor $\leq 6.5 \mathrm{~cm}$ or $\leq 3$ nodules with the largest $\leq 4.5 \mathrm{~cm}$ and a total tumor burden $\leq 8 \mathrm{~cm}$ had 5-year survival rates of 75.2\% after transplant, again equivalent to those patients transplanted without HCC or with HCC within Milan criteria. These expanded criteria, known as the UCSF criteria, in some studies have been shown to select patients with HCC for transplant who have similar survival rates to those with tumor burden within Milan 
criteria, while others have shown dramatically worse 5-year outcomes. $^{45-47}$

More than tumor burden alone, pathologic factors such as vascular invasion and tumor differentiation have been shown to be more predictive of posttransplant mortality. ${ }^{48,49}$ The risk for vascular invasion increases with tumor burden, therefore making many apprehensive to liberalize HCC listing criteria given the paucity of donor livers. ${ }^{50}$

Those patients who are listed for liver transplantation due to HCC derive a mortality benefit from tumor therapy while on the waitlist. The most common treatments are locoregional therapies and include radiofrequency ablation, or TACE, transarterial radioembolization (TARE) or external beam radiation (EBR). ${ }^{51}$ These adjuvant therapies can also be utilized in patients with an intermediate tumor burden outside of Milan criteria to downstage the HCC so that it falls within Milan criteria, or for patients who are not transplant candidates as primary HCC treatment. Patients who have HCC that has been successfully downstaged, have similar posttransplant outcomes as those whose original tumor burden was within Milan criteria. ${ }^{52-54}$

\section{Percutaneous ethanol injection}

Percutaneous therapies, typically chemical or thermal destruction of tumor cells under direct visualization, are a mainstay of early HCC management as well as neoadjuvant therapy prior to transplant. The most common chemical substance injected is ethanol which causes cellular dehydration, protein denaturation and chemical occlusion of small tumor vessels within the tumor to results in necrosis. ${ }^{55}$ Percutaneous ethanol injection is most effective in lesions $<3 \mathrm{~cm}$ which can have a rate of response greater than $80 \% .^{56}$ In larger lesions the rate of recurrence was greater than $30 \% .^{57}$ Child-Pugh A cirrhotic patients who experience therapeutic response to ethanol ablation have a 5-year survival of approximately 50\%. Despite the need for multiple treatments to obtain necrosis, treatments were associated with a $1.7 \%$ risk of severe complications and a $0.1 \%$ mortality rate. ${ }^{58}$ Percutaneous ethanol injection has largely been supplanted by thermal therapies, given the improved local control with thermal therapies. ${ }^{59}$

\section{Thermal ablation}

Multiple modalities exist for thermal ablation of HCC including laser, cryoablation, microwave and radiofrequency ablation (RFA). The most well studied modality is RFA which induces thermal injury via electromagnetic energy dispersal through a directly placed electrode into tumor tissue. ${ }^{55}$ It is a more effective percutaneous therapy than ethanol ablation due to the need for fewer treatments, similar rates of response in HCCs $<3 \mathrm{~cm}$, and with superior prevention of local cancer free and overall survival. ${ }^{60-62}$ The drawbacks of RFA include possible heat damage to surrounding organs therefore preventing treatment of lesions close to the kidney, colon, bile ducts, or gallbladder. An- other drawback of RFA is the "heat sink" effect, which prevents treatment of lesions close to large blood vessels, because blood flow cools the surrounding area and prevents heating to the level needed for tumor destruction. Adverse events are encountered in up to $10 \%$ of cases and include pleural effusions, ascites, tumor seeding and peritoneal bleeding. Mortality rates have been reported as high as $0.3 \% .^{63,64}$ Comparisons between RFA and surgical resection in HCCs $<2 \mathrm{~cm}$ have shown that there is less morbidity associated with RFA without differences in survival rates. ${ }^{65-67}$ Microwave ablation, another method of thermal percutaneous ablation has been shown in some studies to have a similar efficacy as RFA without the concern for the heat sink effect or vascular damage, however in one randomized control trial, it was found to have more adverse events than RFA overall, required more sessions to attain treatment response and had a lower overall survival. ${ }^{68-70}$ In some centers, RFA is the treatment of choice in small, unifocal HCCs, however it is not the standard of care. ${ }^{71}$ It is more commonly utilized to treat those with a single HCC $<3 \mathrm{~cm}$ in whom resection is not a consideration, or as a bridge to liver transplant., ${ }^{3,72}$

\section{TACE}

TACE is currently the most commonly utilized mode of locoregional therapy prior to liver transplant. TACE is performed through the injection of chemotherapy followed by the selective obstruction of a hepatic artery branch which feeds a HCC. As HCC derives the majority of its blood supply from the hepatic artery, occlusion results in ischemic necrosis and slow tumor progression. TACE is traditionally performed with a combination of doxorubicin, mitomycin and/or cisplatin mixed with lipiodol, to aid in retention of the medication within the tumor, followed by a gelatin sponge, for embolization. ${ }^{73}$ TACE results in improved overall 2-year survival when compared with no treatment. ${ }^{7475}$ Response to TACE has been found to be an independent predictor of survival. ${ }^{74}$ Those patients who are best suited for treatment with TACE are those with preserved hepatic function, multifocal or large unifocal, asymptomatic HCC, who are without vascular invasion, but are not candidates for resection. The reported rate of objective response to TACE ranges between $16 \%-60 \%$ and $<2 \%$ have a complete response to treatment. In the large majority of patients, residual tumor cells recover their blood supply and then replicate subsequently necessitating further treatment. ${ }^{73}$ TACE treatments are complicated by risk of ischemic damage resulting in hepatic decompensation, passage of the chemotherapy into systemic circulation as well as postembolic syndrome which causes fever, abdominal pain, and ileus.

TACE with drug-eluting beads (DEB) were shown in preclinical studies to deliver a higher concentration of chemotherapy to the tumor with lower systemic concentrations than conventional TACE. Currently two products exist; DC beads which are polyvinyl alcohol based beads and superabsorbent polymer (SAP) 
microspheres. DC beads have been studied in an international, randomized, control trial, the PRECISION V trial, which found that DC beads versus conventional TACE resulted in comparable control of disease. In a subset analysis, patients with ChildPugh B cirrhosis, ECOG1, and bilobar or recurrent disease had statistically higher disease control rates as compared with conventional TACE. ${ }^{76}$ DC bead TACE also had lower rates or cardiac and hepatotoxicity. ${ }^{77}$ It has been successfully utilized as a bridging therapy to liver transplantation. ${ }^{78,79}$ In an Asian population, DC bead TACE was found to have improved treatment response and delayed progression of HCC as compared to conventional TACE. ${ }^{79}$ These results were not corroborated in a randomized, control trial from the PRECISION ITALIA group which found no survival benefit of DC bead versus conventional TACE. ${ }^{80}$

Midterm analysis of TACE with SAP microspheres indicate that they are safe to use in Child-Pugh B cirrhotics as well as those who are Child-Pugh A with macrovascular invasion. Disease control after the first SAP microsphere TACE was 80\% and a mean overall survival of 20.5 months was noted. ${ }^{81}$ However, there has not yet been a study comparing SAP microspheres with DC beads and conventional TACE. Newer generation DEBs are currently being studied. Early results show decreased number of procedures needed for disease control and a favorable safety profile; however, more studies are needed before DEB TACE can be recommended over conventional TACE. ${ }^{82}$

TACE is typically recommended by the BCLC staging system, for patients with stage B disease (Child-Pugh A-B with ECOG PS 0, multinodular or unresectable tumors, no portal vein invasion and no metastases). Those HCC encompassed by BCLC stage B are felt to be $10 \%$ to $15 \%$ of HCC patients and represents a rather heterogeneous population. This was recognized by a panel of experts who in 2012 created the stage B subclassifications; however, these subclasses have not proven to be clinically significant when applied in retrospective studies. ${ }^{83-85}$ The Hepatoma Arterial-embolization Prognostic score is similarly aims to identify BCLC stage B patients who are best suited for TACE and is currently being studied in independent cohorts. ${ }^{86,87}$

One scoring system which has been externally validated is the selection for transarterial chemoembolization treatment (STATE) score. The score is based on serum albumin level $(\mathrm{g} / \mathrm{L})$ with 12 points subtracted if the tumor burden is outside of up-to-7 criteria and another 12 points subtracted if the C-reactive protein (CRP) is $\geq 1 \mathrm{mg} / \mathrm{dL}$. Those with a STATE score $<18$ had increased mortality of 39\% after a first TACE as opposed to those with a score $\geq 18$ who had a mortality of $14 \%$. $^{88}$

STATE score=serum albumin $(\mathrm{g} / \mathrm{L})-$

12 (if HCC out of up to 7 criteria)-12 (if CRP $\geq 1 \mathrm{mg} / \mathrm{dL}$ )

Score: $<18=$ increased mortality

$\geq 8=$ better candidate for TACE

Most patients require more than one treatment with TACE; however, not all patients benefit from continued TACE therapy. To help differentiate those who derive benefit from TACE versus those who will not, the assessment for retreatment (ART) with TACE score was developed. This score takes into account radiologic tumor response to prior TACE, impairment of liver function due to TACE as shown by a change in Child-Pugh class or an elevation in AST. Two groups are identified, those with a score from 0 to 1.5 derive a benefit from repeat TACE. ${ }^{89}$ This score was later validated for sequential assessment to determine utility of subsequent TACE sessions. ${ }^{90}$ The $\alpha$-fetoprotein, BCLC, Child-Pugh and Response (ABCR) score was also formulated to be calculated prior to a second planned TACE to predict survival. The authors who developed the ABCR score performed an external validation as well as a comparison to the ART score and found that the ABCR score was superior in its ability to predict survival. ${ }^{91}$ Before either score can be utilized clinically prospective studies need to be performed.

\section{Radiation therapy}

TARE involved the deposition of radioactive insoluble microspheres directly to an HCC via the segmental hepatic artery. Typically, the radioactive material utilized is yttrium-90 which is a $\beta$ emitter that induces local tumor necrosis. ${ }^{92}$ Median survival after TARE in patients with intermediate HCC is 9-16 and 6-10 months in those with advanced disease. ${ }^{93}$ TARE can be used in HCC with portal vein thrombosis without compromising blood flow to surrounding hepatic tissue and is safely used in elderly patients. ${ }^{94-96}$ When compared with TACE, TARE has shown similar response, however had a longer time to progression of 13.3 months versus 8.4 months for TACE. ${ }^{97}$ When utilized for tumor downstaging, TARE had improved partial response and successful downstaging rates than TACE. ${ }^{98}$ The most common adverse events encountered with TARE are fatigue, nausea, vomiting and abdominal pain and lower rates of postembolization syndrome than seen with TACE. There were also grade 3 or higher elevations in bilirubin which are thought to reflect potential treatment toxicity. Factors that independently predicted worse survival were ECOG status, $>5$ tumor nodules, an international normalized ratio $>1,2$ and extrahepatic disease. ${ }^{95}$ Currently TARE is utilized in downstaging HCC, or the treatment of BCLC stage $\mathrm{B}$ or $\mathrm{C}$ lesions not amenable to TACE, however there are no formal recommendations from the AASLD for the use of TARE due to a lack of clinical trials. ${ }^{3}$ A randomized clinical trial, the PREMIERE trial comparing TACE to TARE is currently ongoing which should help to determine which modality is better for tumor control and downstaging. ${ }^{99}$

External beam radiation therapy (EBRT) previously had limited use in the treatment of HCC despite tumor response to due to limited radiation tolerance of adjacent hepatic parenchyma. ${ }^{100}$ The development of stereotactic body radiation therapy which has improved targeting precision has enabled the use of external radiation in the treatment of HCC. In a phase II clinical 
trial, three-dimensional conformal radiotherapy used to treat small HCC (one lesion $\leq 5 \mathrm{~cm}$ or two nodules $\leq 3 \mathrm{~cm}$ ) resulted in a tumor response in $92 \%$ of patients and the remaining $8 \%$ had stable disease. Grade 4 toxicities were noted in $22 \%$ of patients, however all were Child-Pugh B cirrhotics, whereas Child-Pugh A cirrhotics tolerated the treatment well. ${ }^{101}$ Radiotherapy has also been utilizes as a bridging therapy to liver transplant. In multiple small studies of patients who had no response or were not candidates for other therapies, no progression of the tumors treated was noted, most had at least 10\% regression and some had complete necrosis of the lesion. ${ }^{102,103}$ Treatment was typically well tolerated with mild side effects such as nausea and thrombocytopenia. More commonly, radiotherapy is utilized in conjunction with other therapies such as TACE or sorafenib.

\section{Systemic therapy}

Sorafenib is an oral multikinase inhibitor which has antiangiogenic activity. This allows the medication to attenuate HCC cell proliferation and progression. In patients with advanced stage HCC it provides a survival benefit. ${ }^{13,104}$ The SHARP trial was a multicenter, double-blind, placebo-controlled trial which found that sorafenib increased median survival from 7.9 months in the placebo group to 10.7 months in the treatment group. Full dose therapy can be difficult to tolerate due to diarrhea, fatigue and hand foot skin reaction. ${ }^{13}$ In an Italian observational study, 91\% of patients experienced an adverse events and 54\% had to dose reduce the sorafenib and $40 \%$ had a treatment interruption as a result. Even in those who required a dose reduction, a survival benefit over placebo was observed. ${ }^{105}$

Sorafenib acts to block several tyrosine kinase receptors; however, not all tumors are responsive to the multikinase inhibition. Another tyrosine kinase that has been implicated in the pathogenesis of HCC is the cellular mesenchymal-epithelial transition (cMET) factor. cMET has a high affinity for hepatocyte growth factor and is involved in tumor growth, migration, survival, and invasion. ${ }^{106}$ Expression is often seen in HCCs that are poorly responsive to sorafenib. Tivantinib is an orally bioavailable MET kinase inhibitor that disrupts the cMET pathway. It is primarily being studied as a second-line agent for HCC after sorafenib failure and has shown increased survival rates in phase II studies. Phase III studies are currently ongoing. ${ }^{107}$

The multimodality approach to HCC therapy has gained more popularity as more treatment options become available and has proven to be more effective than single modality therapy in tumor downstaging prior to liver transplantation. ${ }^{108,109}$ Studies are currently ongoing investigating specific combinations in the treatment of HCC.

The combination of sorafenib with TACE has had inconsistent results. When given sequentially, TACE followed by sorafenib has not clearly shown a benefit in time to progression. ${ }^{10,111}$ When given simultaneously, similar issues have arisen, however the trend is toward benefit with combination TACE and sorafenib. The largest trial to date is the SPACE trial which evaluated 307 patients and found no superiority for TACE and sorafenib compared to sorafenib alone. ${ }^{112}$ However on subgroup analysis of patients from Asia where the duration of combination therapy was higher, showed a benefit in TACE and sorafenib therapy. ${ }^{113}$ The START trial which evaluated combination therapy with TACE and sorafenib in 192 Asian patients with HCC found that $69.4 \%$ of patients responded to therapy and 52.6\% achieved a complete response, however the main focus of the study was safety and tolerability, and although efficacy was a primary objective, there was no control group with which to compare. ${ }^{114}$ In Asian patients with advanced stage HCC or tumor thrombosis not involving the main portal vein, sorafenib and TACE has been shown to improve survival when compared to TACE alone. ${ }^{115,116}$

TACE followed by stereotactic radiotherapy for nonresectable HCCs has shown in small studies to decrease local tumor recurrence and increase overall survival. ${ }^{117}$ Choi et al. ${ }^{118}$ studied 31 patients with HCC some with small HCCs and others with advanced tumor and portal vein thrombosis. Overall response to therapy with radiotherapy and TACE was $71.9 \%$ with rates higher in those with small HCC versus advanced disease. Another study of patients with HCC and portal vein thrombus there has been a $39.6 \%$ and progression-free survival of $85.6 \%$, however hepatotoxicity in 10\%. ${ }^{119}$ Larger randomized controlled trials are needed to determine if combining TACE and EBR is a safe and effective combination.

Hepatocellular carcinoma continues to be a leading cause of cancer death worldwide. Multiple therapies exist for the treatment of hepatocellular carcinoma, however are not universally applicable to treat all patients. HCC typically arises in a background of chronic liver disease and is often discovered at later stages of disease making treatment choices more complex. Staging systems help guide clinicians in their treatment choices which are often made by multidisciplinary tumor boards. However, ongoing research elucidates exact populations in which specific therapies are preferred and therapeutic combinations which may be most beneficial further improving our ability to treat HCC.

\section{CONFLICTS OF INTEREST}

No potential conflict of interest relevant to this article was reported.

\section{REFERENCES}

1. International Agency for Research on Cancer. GLOBOCAN 2012: estimated cancer incidence, mortality and prevalence worldwide in 2012 [Internet]. Lyon: International Agency for Research on Cancer; c2014 [cited 2014 Dec 1]. Available from: http://globocan. iarc.fr/Pages/fact_sheets_cancer.aspx. 
2. American Cancer Society. Cancer facts \& figures 2014 [Internet]. Atlanta: American Cancer Society; 2014 [cited 2014 Dec 4]. Available from: http://www.cancer.org/acs/groups/content/@ research/documents/webcontent/acspc-042151.pdf.

3. Bruix J, Sherman M; Practice Guidelines Committee, American Association for the Study of Liver Diseases. Management of hepatocellular carcinoma. Hepatology 2005;42:1208-1236.

4. European Association for the Study of the Liver; European Organisation tor Research and Treatment of Cancer. EASL-EORTC clinical practice guidelines: management of hepatocellular carcinoma. J Hepatol 2012;56:908-943.

5. Llovet JM, Burroughs A, Bruix J. Hepatocellular carcinoma. Lancet 2003;362:1907-1917.

6. Greene FL, Sobin LH. The staging of cancer: a retrospective and prospective appraisal. CA Cancer J Clin 2008;58:180-190.

7. Leung TW, Tang AM, Zee B, et al. Construction of the Chinese University Prognostic Index for hepatocellular carcinoma and comparison with the TNM staging system, the Okuda staging system, and the Cancer of the Liver Italian Program staging system: a study based on 926 patients. Cancer 2002;94:1760-1769.

8. Okuda K, Ohtsuki T, Obata H, et al. Natural history of hepatocellular carcinoma and prognosis in relation to treatment: study of 850 patients. Cancer 1985;56:918-928.

9. Grieco A, Pompili M, Caminiti G, et al. Prognostic factors for survival in patients with early-intermediate hepatocellular carcinoma undergoing non-surgical therapy: comparison of Okuda, CLIP, and BCLC staging systems in a single Italian centre. Gut 2005;54:411-418

10. Kudo M, Chung H, Osaki Y. Prognostic staging system for hepatocellular carcinoma (CLIP score): its value and limitations, and a proposal for a new staging system, the Japan Integrated Staging Score (JIS score). J Gastroenterol 2003;38:207-215.

11. Chevret S, Trinchet JC, Mathieu D, Rached AA, Beaugrand M, Chastang C. A new prognostic classification for predicting survival in patients with hepatocellular carcinoma. Groupe d'Etude et de Traitement du Carcinome Hépatocellulaire. J Hepatol 1999;31: 133-141.

12. Llovet JM, Fuster J, Bruix J; Barcelona-Clínic Liver Cancer Group. The Barcelona approach: diagnosis, staging, and treatment of hepatocellular carcinoma. Liver Transpl 2004;10(2 Suppl 1):S115S120.

13. Llovet JM, Ricci S, Mazzaferro V, et al. Sorafenib in advanced hepatocellular carcinoma. N Engl J Med 2008;359:378-390.

14. Llovet JM, Real MI, Montaña X, et al. Arterial embolisation or chemoembolisation versus symptomatic treatment in patients with unresectable hepatocellular carcinoma: a randomised controlled trial. Lancet 2002;359:1734-1739.

15. Cillo U, Vitale A, Grigoletto F, et al. Prospective validation of the Barcelona Clinic Liver Cancer staging system. J Hepatol 2006; 44:723-731.

16. Yau T, Tang VY, Yao TJ, Fan ST, Lo CM, Poon RT. Development of Hong Kong Liver Cancer staging system with treatment strati- fication for patients with hepatocellular carcinoma. Gastroenterology 2014;146:1691-1700.e3.

17. Naugler WE, Alsina AE, Frenette CT, Rossaro L, Sellers MT. Building the multidisciplinary team for management of patients with hepatocellular carcinoma. Clin Gastroenterol Hepatol 2015;13: 827-835.

18. Chang TT, Sawhney R, Monto A, et al. Implementation of a multidisciplinary treatment team for hepatocellular cancer at a Veterans Affairs Medical Center improves survival. HPB (Oxford) 2008;10:405-411.

19. Chan SL, Mo FK, Johnson PJ, et al. Prospective validation of the Chinese University Prognostic Index and comparison with other staging systems for hepatocellular carcinoma in an Asian population. J Gastroenterol Hepatol 2011;26:340-347.

20. Kluger MD, Salceda JA, Laurent A, et al. Liver resection for hepatocellular carcinoma in 313 Western patients: tumor biology and underlying liver rather than tumor size drive prognosis. J Hepatol 2015;62:1131-1140

21. Llovet JM, Fuster J, Bruix J. Intention-to-treat analysis of surgical treatment for early hepatocellular carcinoma: resection versus transplantation. Hepatology 1999;30:1434-1440.

22. Lai EC, Fan ST, Lo CM, Chu KM, Liu CL, Wong J. Hepatic resection for hepatocellular carcinoma: an audit of 343 patients. Ann Surg 1995;221:291-298.

23. Zhou WP, Lai EC, Li AJ, et al. A prospective, randomized, controlled trial of preoperative transarterial chemoembolization for resectable large hepatocellular carcinoma. Ann Surg 2009;249: 195-202.

24. Yamasaki S, Hasegawa H, Kinoshita H, et al. A prospective randomized trial of the preventive effect of pre-operative transcatheter arterial embolization against recurrence of hepatocellular carcinoma. Jpn J Cancer Res 1996;87:206-211.

25. Wu CC, Ho YZ, Ho WL, Wu TC, Liu TJ, P'eng FK. Preoperative transcatheter arterial chemoembolization for resectable large hepatocellular carcinoma: a reappraisal. Br J Surg 1995;82:122126.

26. Xie F, Zhang X, Li H, et al. Adoptive immunotherapy in postoperative hepatocellular carcinoma: a systemic review. PLoS One 2012;7:e42879.

27. Samuel M, Chow PK, Chan Shih-Yen E, Machin D, Soo KC. Neoadjuvant and adjuvant therapy for surgical resection of hepatocellular carcinoma. Cochrane Database Syst Rev 2009; (1):CD001199.

28. Lau WY, Leung TW, Ho SK, et al. Adjuvant intra-arterial iodine131-labelled lipiodol for resectable hepatocellular carcinoma: a prospective randomised trial. Lancet 1999;353:797-801.

29. Takayama T, Sekine T, Makuuchi M, et al. Adoptive immunotherapy to lower postsurgical recurrence rates of hepatocellular carcinoma: a randomised trial. Lancet 2000;356:802-807.

30. Muto Y, Moriwaki H, Ninomiya M, et al. Prevention of second primary tumors by an acyclic retinoid, polyprenoic acid, in patients with hepatocellular carcinoma. Hepatoma Prevention Study 
Group. N Engl J Med 1996;334:1561-1567.

31. Wang J, He XD, Yao N, Liang WJ, Zhang YC. A meta-analysis of adjuvant therapy after potentially curative treatment for hepatocellular carcinoma. Can J Gastroenterol 2013;27:351-363.

32. Shen YC, Hsu C, Chen LT, Cheng CC, Hu FC, Cheng AL. Adjuvant interferon therapy after curative therapy for hepatocellular carcinoma (HCC): a meta-regression approach. J Hepatol 2010;52:889894.

33. Breitenstein S, Dimitroulis D, Petrowsky H, Puhan MA, Müllhaupt B, Clavien PA. Systematic review and meta-analysis of interferon after curative treatment of hepatocellular carcinoma in patients with viral hepatitis. Br J Surg 2009;96:975-981.

34. Poon RT, Fan ST, Lo CM, Liu CL, Wong J. Long-term survival and pattern of recurrence after resection of small hepatocellular carcinoma in patients with preserved liver function: implications for a strategy of salvage transplantation. Ann Surg 2002;235:373-382.

35. Iwatsuki S, Klintmalm GB, Starzl TE. Total hepatectomy and liver replacement (orthotopic liver transplantation) for primary hepatic malignancy. World J Surg 1982;6:81-85.

36. Calne RY, Williams R. Orthotopic liver transplantation: the first 60 patients. Br Med J 1977;1:471-476.

37. Iwatsuki S, Gordon RD, Shaw BW Jr, Starzl TE. Role of liver transplantation in cancer therapy. Ann Surg 1985;202:401-407.

38. Mazzaferro V, Regalia E, Doci R, et al. Liver transplantation for the treatment of small hepatocellular carcinomas in patients with cirrhosis. N Engl J Med 1996;334:693-699.

39. Ioannou GN, Perkins JD, Carithers RL Jr. Liver transplantation for hepatocellular carcinoma: impact of the MELD allocation system and predictors of survival. Gastroenterology 2008;134:13421351.

40. Washburn K, Edwards E, Harper A, Freeman R. Hepatocellular carcinoma patients are advantaged in the current liver transplant allocation system. Am J Transplant 2010;10:1643-1648.

41. Northup PG, Berg CL. Hepatocellular carcinoma and model for end-stage liver disease exceptions: the more we understand, the more challenging the allocation gets. Liver Transpl 2012;18:381383.

42. Goldberg D, French B, Abt P, Feng S, Cameron AM. Increasing disparity in waitlist mortality rates with increased model for endstage liver disease scores for candidates with hepatocellular carcinoma versus candidates without hepatocellular carcinoma. Liver Transpl 2012;18:434-443.

43. Schuetz C, Dong N, Smoot E, et al. HCC patients suffer less from geographic differences in organ availability. Am J Transplant 2013;13:2989-2995.

44. Yao FY, Ferrell L, Bass NM, et al. Liver transplantation for hepatocellular carcinoma: expansion of the tumor size limits does not adversely impact survival. Hepatology 2001;33:1394-1403.

45. Yao FY, Ferrell L, Bass NM, Bacchetti P, Ascher NL, Roberts JP. Liver transplantation for hepatocellular carcinoma: comparison of the proposed UCSF criteria with the Milan criteria and the Pittsburgh modified TNM criteria. Liver Transpl 2002;8:765-774.
46. Duffy JP, Vardanian A, Benjamin E, et al. Liver transplantation criteria for hepatocellular carcinoma should be expanded: a 22year experience with 467 patients at UCLA. Ann Surg 2007; 246:502-509.

47. Decaens T, Roudot-Thoraval F, Hadni-Bresson S, et al. Impact of UCSF criteria according to pre- and post-OLT tumor features: analysis of 479 patients listed for HCC with a short waiting time. Liver Transpl 2006;12:1761-1769.

48. Yuki K, Hirohashi S, Sakamoto M, Kanai T, Shimosato Y. Growth and spread of hepatocellular carcinoma: a review of 240 consecutive autopsy cases. Cancer 1990;66:2174-2179.

49. Zavaglia C, De Carlis L, Alberti AB, et al. Predictors of long-term survival after liver transplantation for hepatocellular carcinoma. Am J Gastroenterol 2005;100:2708-2716.

50. Jonas S, Bechstein WO, Steinmüller T, et al. Vascular invasion and histopathologic grading determine outcome after liver transplantation for hepatocellular carcinoma in cirrhosis. Hepatology 2001;33:1080-1086.

51. Llovet JM, Mas X, Aponte JJ, et al. Cost effectiveness of adjuvant therapy for hepatocellular carcinoma during the waiting list for liver transplantation. Gut 2002;50:123-128.

52. Ravaioli M, Grazi GL, Piscaglia F, et al. Liver transplantation for hepatocellular carcinoma: results of down-staging in patients initially outside the Milan selection criteria. Am J Transplant 2008; 8:2547-2557.

53. Yao FY, Hirose R, LaBerge JM, et al. A prospective study on downstaging of hepatocellular carcinoma prior to liver transplantation. Liver Transpl 2005;11:1505-1514.

54. Yu CY, Ou HY, Huang TL, et al. Hepatocellular carcinoma downstaging in liver transplantation. Transplant Proc 2012;44:412414.

55. Lencioni R. Loco-regional treatment of hepatocellular carcinoma. Hepatology 2010;52:762-773.

56. Kuang M, Lu MD, Xie XY, et al. Ethanol ablation of hepatocellular carcinoma up to $5.0 \mathrm{~cm}$ by using a multipronged injection needle with high-dose strategy. Radiology 2009;253:552-561.

57. Ishii H, Okada S, Nose H, et al. Local recurrence of hepatocellular carcinoma after percutaneous ethanol injection. Cancer 1996; 77:1792-1796.

58. Livraghi T, Giorgio A, Marin G, et al. Hepatocellular carcinoma and cirrhosis in 746 patients: long-term results of percutaneous ethanol injection. Radiology 1995;197:101-108.

59. Livraghi T, Goldberg SN, Lazzaroni S, Meloni F, Solbiati L, Gazelle GS. Small hepatocellular carcinoma: treatment with radiofrequency ablation versus ethanol injection. Radiology 1999; 210:655-661.

60. Lencioni RA, Allgaier HP, Cioni D, et al. Small hepatocellular carcinoma in cirrhosis: randomized comparison of radio-frequency thermal ablation versus percutaneous ethanol injection. Radiology 2003;228:235-240.

61. Lin SM, Lin CJ, Lin CC, Hsu CW, Chen YC. Radiofrequency ablation improves prognosis compared with ethanol injection for he- 
patocellular carcinoma $<$ or $=4 \mathrm{~cm}$. Gastroenterology 2004;127: 1714-1723.

62. Orlando A, Leandro G, Olivo M, Andriulli A, Cottone M. Radiofrequency thermal ablation vs. percutaneous ethanol injection for small hepatocellular carcinoma in cirrhosis: meta-analysis of randomized controlled trials. Am J Gastroenterol 2009;104:514524.

63. Shiina S, Teratani T, Obi S, et al. A randomized controlled trial of radiofrequency ablation with ethanol injection for small hepatocellular carcinoma. Gastroenterology 2005;129:122-130.

64. Giorgio A, Tarantino L, de Stefano G, Coppola C, Ferraioli G. Complications after percutaneous saline-enhanced radiofrequency ablation of liver tumors: 3-year experience with 336 patients at a single center. AJR Am J Roentgenol 2005;184:207-211.

65. Livraghi T, Meloni F, Di Stasi M, et al. Sustained complete response and complications rates after radiofrequency ablation of very early hepatocellular carcinoma in cirrhosis: is resection still the treatment of choice? Hepatology 2008;47:82-89.

66. Chen MS, Li JQ, Zheng Y, et al. A prospective randomized trial comparing percutaneous local ablative therapy and partial hepatectomy for small hepatocellular carcinoma. Ann Surg 2006; 243:321-328

67. Lü MD, Kuang M, Liang LJ, et al. Surgical resection versus percutaneous thermal ablation for early-stage hepatocellular carcinoma: a randomized clinical trial. Zhonghua Yi Xue Za Zhi 2006; 86:801-805.

68. Ohmoto K, Yoshioka N, Tomiyama Y, et al. Comparison of therapeutic effects between radiofrequency ablation and percutaneous microwave coagulation therapy for small hepatocellular carcinomas. J Gastroenterol Hepatol 2009;24:223-227.

69. Liang P, Wang Y. Microwave ablation of hepatocellular carcinoma. Oncology 2007;72 Suppl 1:124-131.

70. Shibata T, Iimuro Y, Yamamoto Y, et al. Small hepatocellular carcinoma: comparison of radio-frequency ablation and percutaneous microwave coagulation therapy. Radiology 2002;223:331337.

71. Choi D, Lim HK, Rhim H, et al. Percutaneous radiofrequency ablation for early-stage hepatocellular carcinoma as a first-line treatment: long-term results and prognostic factors in a large single-institution series. Eur Radiol 2007;17:684-692.

72. Mazzaferro V, Battiston C, Perrone S, et al. Radiofrequency ablation of small hepatocellular carcinoma in cirrhotic patients awaiting liver transplantation: a prospective study. Ann Surg 2004; 240:900-909.

73. Bruix J, Sala M, Llovet JM. Chemoembolization for hepatocellular carcinoma. Gastroenterology 2004;127(5 Suppl 1):S179-S188.

74. Llovet JM, Bruix J. Systematic review of randomized trials for unresectable hepatocellular carcinoma: chemoembolization improves survival. Hepatology 2003;37:429-442.

75. Cammà C, Schepis F, Orlando A, et al. Transarterial chemoembolization for unresectable hepatocellular carcinoma: meta-analysis of randomized controlled trials. Radiology 2002;224:47-54.
76. Lammer J, Malagari K, Vogl T, et al. Prospective randomized study of doxorubicin-eluting-bead embolization in the treatment of hepatocellular carcinoma: results of the PRECISION V study. Cardiovasc Intervent Radiol 2010;33:41-52.

77. Vogl TJ, Lammer J, Lencioni R, et al. Liver, gastrointestinal, and cardiac toxicity in intermediate hepatocellular carcinoma treated with PRECISION TACE with drug-eluting beads: results from the PRECISION V randomized trial. AJR Am J Roentgenol 2011;197:W562-W570.

78. Green TJ, Rochon PJ, Chang S, et al. Downstaging disease in patients with hepatocellular carcinoma outside of Milan criteria: strategies using drug-eluting bead chemoembolization. J Vasc Interv Radiol 2013;24:1613-1622.

79. Song MJ, Chun HJ, Song do S, et al. Comparative study between doxorubicin-eluting beads and conventional transarterial chemoembolization for treatment of hepatocellular carcinoma. J Hepatol 2012;57:1244-1250.

80. Golfieri R, Giampalma E, Renzulli M, et al. Randomised controlled trial of doxorubicin-eluting beads vs conventional chemoembolisation for hepatocellular carcinoma. Br J Cancer 2014;111:255264.

81. Dekervel J, van Malenstein H, Vandecaveye V, et al. Transcatheter arterial chemoembolization with doxorubicin-eluting superabsorbent polymer microspheres in the treatment of hepatocellular carcinoma: midterm follow-up. J Vasc Interv Radiol 2014;25: 248-255.e1.

82. Spreafico C, Cascella T, Facciorusso A, et al. Transarterial chemoembolization for hepatocellular carcinoma with a new generation of beads: clinical-radiological outcomes and safety profile. Cardiovasc Intervent Radiol 2015;38:129-134.

83. Bolondi L, Burroughs A, Dufour JF, et al. Heterogeneity of patients with intermediate (BCLC B) hepatocellular carcinoma: proposal for a subclassification to facilitate treatment decisions. Semin Liver Dis 2012;32:348-359.

84. Weinmann A, Koch S, Sprinzl M, et al. Survival analysis of proposed BCLC-B subgroups in hepatocellular carcinoma patients. Liver Int 2015;35:591-600.

85. Ha Y, Shim JH, Kim SO, Kim KM, Lim YS, Lee HC. Clinical appraisal of the recently proposed Barcelona Clinic Liver Cancer stage B subclassification by survival analysis. J Gastroenterol Hepatol 2014;29:787-793.

86. Kadalayil L, Benini R, Pallan L, et al. A simple prognostic scoring system for patients receiving transarterial embolisation for hepatocellular cancer. Ann Oncol 2013;24:2565-2570.

87. Noorullah 0, Lekharaju VP, Uddin I, et al. Mo1046 an external validation of the hepatoma arterial-embolisation prognosis (Hap) score: the Liverpool experience. Gastroenterology 2014;146(5 Suppl 1): S995.

88. Hucke F, Pinter M, Graziadei I, et al. How to STATE suitability and START transarterial chemoembolization in patients with intermediate stage hepatocellular carcinoma. J Hepatol 2014;61:12871296. 
89. Sieghart W, Hucke F, Pinter M, et al. The ART of decision making: retreatment with transarterial chemoembolization in patients with hepatocellular carcinoma. Hepatology 2013;57:2261-2273.

90. Hucke F, Sieghart W, Pinter M, et al. The ART-strategy: sequential assessment of the ART score predicts outcome of patients with hepatocellular carcinoma re-treated with TACE. J Hepatol 2014;60:118-126.

91. Adhoute X, Penaranda G, Naude S, et al. Retreatment with TACE: The ABCR SCORE, an aid to the decision-making process. J Hepatol 2015;62:855-862.

92. de Lope CR, Tremosini S, Forner A, Reig M, Bruix J. Management of HCC. J Hepatol 2012;56 Suppl 1:S75-S87.

93. Sangro B, Iñarrairaegui M, Bilbao JI. Radioembolization for hepatocellular carcinoma. J Hepatol 2012;56:464-473.

94. Kulik LM, Carr BI, Mulcahy MF, et al. Safety and efficacy of $90 Y$ radiotherapy for hepatocellular carcinoma with and without portal vein thrombosis. Hepatology 2008;47:71-81.

95. Sangro B, Carpanese L, Cianni R, et al. Survival after yttrium-90 resin microsphere radioembolization of hepatocellular carcinoma across Barcelona Clinic Liver Cancer stages: a European evaluation. Hepatology 2011;54:868-878.

96. Golfieri R, Bilbao JI, Carpanese L, et al. Comparison of the survival and tolerability of radioembolization in elderly vs. younger patients with unresectable hepatocellular carcinoma. J Hepatol 2013;59:753-761.

97. Salem R, Lewandowski RJ, Kulik L, et al. Radioembolization results in longer time-to-progression and reduced toxicity compared with chemoembolization in patients with hepatocellular carcinoma. Gastroenterology 2011;140:497-507.e2.

98. Lewandowski RJ, Kulik LM, Riaz A, et al. A comparative analysis of transarterial downstaging for hepatocellular carcinoma: chemoembolization versus radioembolization. Am J Transplant 2009;9:1920-1928.

99. ClinicalTrials.gov. Identifier NCT00956930, Chemoembolization versus radioembolization in treating patients with liver cancer that cannot be treated with radiofrequency ablation or surgery; 2009 Aug 8 [Internet]. Bethesda: U.S. National Institutes of Health; c2015 [cited 2014 Nov 1]. Available from: https://clinicaltrials.gov/ct2/show/NCT00956930.

100. Fuss M, Salter BJ, Herman TS, Thomas CR Jr. External beam radiation therapy for hepatocellular carcinoma: potential of intensitymodulated and image-guided radiation therapy. Gastroenterology 2004;127(5 Suppl 1):S206-S217.

101. Mornex F, Girard N, Beziat C, et al. Feasibility and efficacy of high-dose three-dimensional-conformal radiotherapy in cirrhotic patients with small-size hepatocellular carcinoma non-eligible for curative therapies: mature results of the French Phase II RTF-1 trial. Int J Radiat Oncol Biol Phys 2006;66:1152-1158.

102. Katz AW, Chawla S, Qu Z, Kashyap R, Milano MT, Hezel AF. Stereotactic hypofractionated radiation therapy as a bridge to transplantation for hepatocellular carcinoma: clinical outcome and pathologic correlation. Int J Radiat Oncol Biol Phys 2012;83:895-
900.

103. Sandroussi C, Dawson LA, Lee M, et al. Radiotherapy as a bridge to liver transplantation for hepatocellular carcinoma. Transpl Int 2010;23:299-306.

104. Cheng AL, Kang YK, Chen Z, et al. Efficacy and safety of sorafenib in patients in the Asia-Pacific region with advanced hepatocellular carcinoma: a phase III randomised, double-blind, placebo-controlled trial. Lancet Oncol 2009;10:25-34.

105. Iavarone M, Cabibbo G, Piscaglia F, et al. Field-practice study of sorafenib therapy for hepatocellular carcinoma: a prospective multicenter study in Italy. Hepatology 2011;54:2055-2063.

106. Boccaccio C, Comoglio PM. Invasive growth: a MET-driven genetic programme for cancer and stem cells. Nat Rev Cancer 2006;6:637645.

107. Au J, Frenette C. Development of tivantinib as treatment for hepatocellular carcinoma. J Clin Transl Hepatol 2013;1:75-78.

108. Yao FY, Kerlan RK Jr, Hirose R, et al. Excellent outcome following down-staging of hepatocellular carcinoma prior to liver transplantation: an intention-to-treat analysis. Hepatology 2008;48:819-827.

109. Ravaioli M, Grazi GL, Piscaglia F, et al. Liver transplantation for hepatocellular carcinoma: results of down-staging in patients initially outside the Milan selection criteria. Am J Transplant 2008;8:2547-2557.

110. Sansonno D, Lauletta G, Russi S, Conteduca V, Sansonno L, Dammacco F. Transarterial chemoembolization plus sorafenib: a sequential therapeutic scheme for HCV-related intermediate-stage hepatocellular carcinoma. A randomized clinical trial. Oncologist 2012;17:359-366.

111. Kudo M, Imanaka K, Chida N, et al. Phase III study of sorafenib after transarterial chemoembolisation in Japanese and Korean patients with unresectable hepatocellular carcinoma. Eur J Cancer 2011;47:2117-2127.

112. Lencioni R, Llovet JM, Han G, et al. Sorafenib or placebo in combination with transarterial chemoembolization (TACE) with doxorubicin-eluting beads (DEBDOX) for intermediate-stage hepatocellular carcinoma (HCC): phase II, randomized, double-blind SPACE trial. J Clin Oncol 2012;30(Suppl 4):LBA154.

113. Hsu C, Po-Ching-Liang, Morita S, Hu FC, Cheng AL. Perspectives on the design of clinical trials combining transarterial chemoembolization and molecular targeted therapy. Liver Cancer 2012;1:168-176.

114. Chao Y, Chung YH, Han G, et al. The combination of transcatheter arterial chemoembolization and sorafenib is well tolerated and effective in Asian patients with hepatocellular carcinoma: final results of the START trial. Int J Cancer 2015;136:1458-1467.

115. Choi GH, Shim JH, Kim MJ, et al. Sorafenib alone versus sorafenib combined with transarterial chemoembolization for advanced-stage hepatocellular carcinoma: results of propensity score analyses. Radiology 2013;269:603-611.

116. Zhu K, Chen J, Lai L, et al. Hepatocellular carcinoma with portal vein tumor thrombus: treatment with transarterial chemoemboli- 
448 Gut and Liver, Vol. 9, No. 4, July 2015

zation combined with sorafenib: a retrospective controlled study. Radiology 2014;272:284-293.

117. Jacob R, Turley F, Redden DT, et al. Adjuvant stereotactic body radiotherapy following transarterial chemoembolization in patients with non-resectable hepatocellular carcinoma tumours of $\geq$ 3 cm. HPB (Oxford) 2015;17:140-149.

118. Choi BO, Choi IB, Jang HS, et al. Stereotactic body radiation ther- apy with or without transarterial chemoembolization for patients with primary hepatocellular carcinoma: preliminary analysis. BMC Cancer 2008;8:351.

119. Yoon SM, Lim YS, Won HJ, et al. Radiotherapy plus transarterial chemoembolization for hepatocellular carcinoma invading the portal vein: long-term patient outcomes. Int J Radiat Oncol Biol Phys 2012;82:2004-2011. 